\title{
The Use of Artificial Neural Networks to Prioritize Impact Factors Affecting Thai Rural Village Development
}

\author{
*Wittaya Pornpatcharapong, Pacapol Jakrapan Anurit, Chuvej Chansa-ngavej, Supachok Wiriyacosol, \\ Chanchai Bunchapattanasakda \\ School of Management, Shinawatra University, Bangkok, Thailand \\ *jowittaya@gmail.com
}

\begin{abstract}
This paper aims to prioritize impact factors which affect Thai rural village development. The basic village-leveled information database (NRD-2C) of the Community Development Department (CDD), Ministry of Interior, Thailand, was applied with Artificial Neural Networks (ANN) to measure the amount of impact for each factor affecting Thai rural village development. According to results, the top 5 impact factors are "Land Possession", "Electricity", "Communication", "Educational Level", and "Household Industry" with 17.88, 15.35, 14.02, 12.06, and 10.57 score of impact respectively with 95.60 percent of estimated accuracy.
\end{abstract}

Keywords: Prioritization, Rural Development, Community Development, Artificial Neural Networks

\section{Introduction}

Human beings have known and learned the development of livelihood since they were born on the earth. As many evidences discovered so far, there have been the evolution of tools, constructions, weapons, clothes, vehicles, etc. Furthermore, much beliefs and teachings of Roman, Greek, Arabic, Chinese, Indian philosophers have been accepted and spread worldwide. So that "Development" has become a science and been adapted into many areas of study. Development has been a key to solve economic crisis such as inflation, economic recession, and unemployment. The Community Development Department of Thailand was established in 1962 under the Ministry of Interior to coordinate with all governors, CDD workers, community leaders and people for collecting community data in rural areas, then analyzing data, reporting useful information and making policies for community development. Community planners and developers have been persistently concerned with building the good community (Grant, 2006).

There are 2 types of Thai rural community database; BMN (Basic Minimum Needs), household-levelled information, and NRD-2C (Basic Village Information), village-levelled information. BMN covers approximately 8 million rural households and is updated every year, and NRD-2C covers 69,763 villages in rural area of Thailand and will be updated every 2 years (Community Development Department, 2007). In this study, only NRD-2C was used to measure the amount of impact of each factor.

\section{Figure 1: NRD-2C Database Overview in 6 Categories}

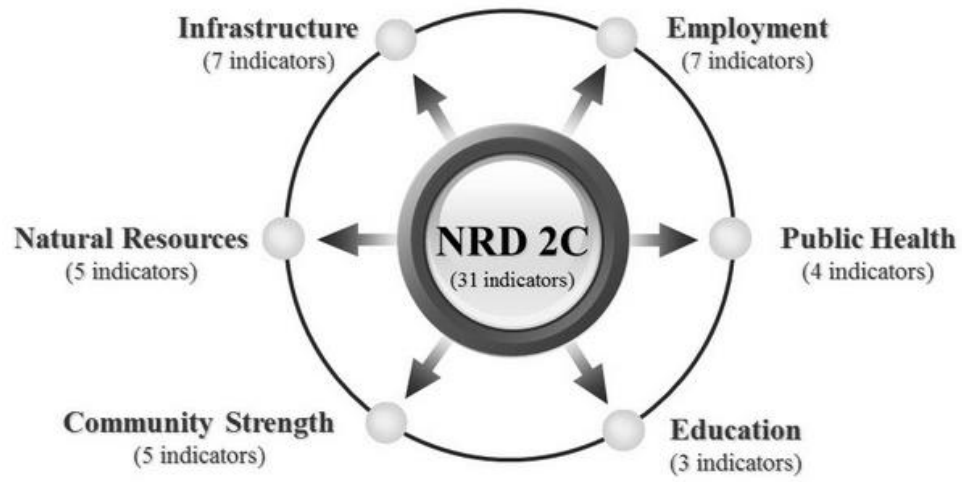

Source: Reproduced from Community Development Department (2003), (NRD2C)

NRD-2C Database contains 31 key performance indicators (factors/variables) which are classified into 6 categories as shown in Figure 1 e.g. 1) Infrastructure, 2) Employment, 3) Public Health, 4) Education, 5) Community Strength, and 6) Natural Resources. So far, CDD has analyzed these databases with only a conventional quantitative analysis. They have only used a Statistical Distribution Analysis to describe and 
classify the development level of villages in Thailand. Then prioritize these factors by using the numbers of villages which failed in each factor. The result is displayed in Table 1 below.

Table 1: A Summary of Factor Prioritization Affecting Thai Rural Development using Statistical Frequency Distribution Analysis (All Categories)

\begin{tabular}{|c|c|c|}
\hline Rank & Factor & $\begin{array}{c}\text { Total Villages Which } \\
\text { Failed (Villages) }\end{array}$ \\
\hline 1 & Learning by A Community & 40,601 \\
\hline 2 & Sports & 36,033 \\
\hline 3 & Soil Quality & 20,849 \\
\hline 4 & Access of A Community's Financial Capital & 16,312 \\
\hline 5 & Being Educated & 15,547 \\
\hline 6 & Products from Other Agriculture & 10,758 \\
\hline 7 & Water for Agriculture & 8,502 \\
\hline 8 & Getting A Job & 7,885 \\
\hline 9 & Products from Farms & 7,450 \\
\hline 10 & Land Possession & 5,847 \\
\hline 11 & Products from Rice & 4,605 \\
\hline 12 & Water Quality & 4,561 \\
\hline 13 & Social Protection & 4,453 \\
\hline 14 & Further Studying beyond Limitation (Grade 9) & 3,958 \\
\hline 15 & Environment Management & 3,459 \\
\hline 16 & People Assembly & 3,048 \\
\hline 17 & Community Participation & 2,972 \\
\hline 18 & Road & 2,817 \\
\hline 19 & Communication Technology Access (TV, Radio, Internet) & 2,593 \\
\hline 20 & Water for Drinking & 2,593 \\
\hline 21 & Household Industry & 2,341 \\
\hline 22 & Working in Establishment & 1,949 \\
\hline 23 & Educational Level & 1,851 \\
\hline 24 & Water for Consumption & 1,815 \\
\hline 25 & Benefits from Tourist Attraction & 1,642 \\
\hline 26 & Electricity Access & 995 \\
\hline 27 & Work Safety & 982 \\
\hline 28 & Afforesting & 849 \\
\hline 29 & Contagious Disease Prevention & 829 \\
\hline 30 & Free from Addictive Drug & 279 \\
\hline 31 & Land Utilization & 2 \\
\hline
\end{tabular}

But in term of impact evaluation, it is not necessary that the impact factor which most number of villages fail in has the most influence on Thai rural village development. On the other hand, the impact factor which has the most influence on Thai rural village development might have fewer number of failing villages. Moreover, all raw data in NRD-2C database were recorded as nominal data type (passed or failed), and the data of village development level were as ordinal data type (level 1, 2, and 3). By Technically, Correlation Analysis and Regression Analysis cannot be used to measure the amount of relationship or weight of impact. Previous studies done by West, Brockett, and Golden (1997); Thieme, Song, and Calantone (2000); Song and Zhao (2004) showed that Artificial Neural Networks (ANN) approach was well suited to complex relationships analysis and well dealt with all data types. It was found that ANN was used to evaluate general relationship quality (Bejou, Wray, and Ingram, 1996). So in this study, ANN was applied to measure the weight of impact for each factor.

\section{Artificial Neural Networks (ANN)}

ANN was applied in two stages: learning and testing. In the learning stage, a set of connection weights was calculated for a given set of input and output values. For back-propagation method, the output set 
contained previously known values. An algorithm called the delta-learning rule was used to adjust the weights at the end of iterations until the output was more similar to the pre-defined output. Learning was complete when the network had learned the relationship between the inputs and outputs. During the learning, setting the number and the size of the hidden neurons was difficult. Hidden layers represented non-linearity or interactions between variables. The more complex interactions, the more hidden neurons were required. In the testing stage, weights calculated during the learning stage were engaged to estimate a new set of output for a given set of input values (Yesilyaprak, 2004) for measuring the estimated accuracy of the analysis.

\section{Figure 2: Basic ANN Structure}

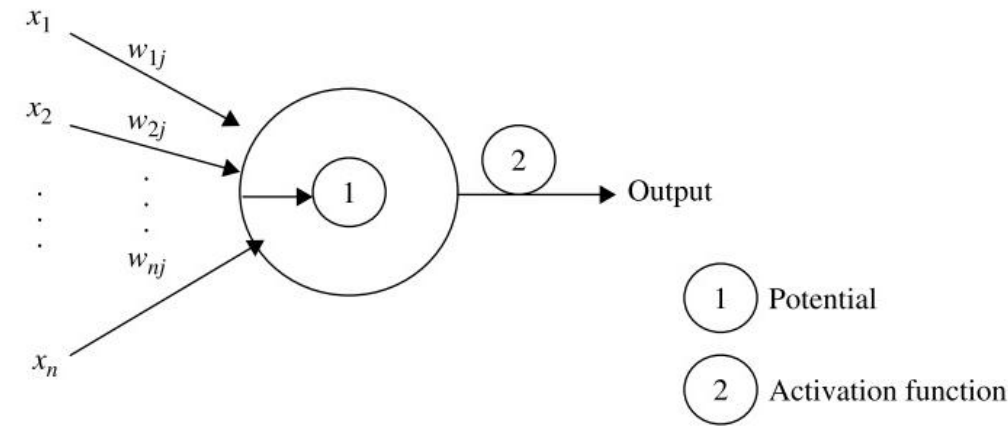

Source: Reproduced from Giudici (2003)

Basically, a generic neuron $j$, with a threshold $\theta j$, received $\mathrm{n}$ input signals $\mathrm{x}=\left[x_{1}, x_{2}, \ldots, x_{n}\right]$ from the units to which it was connected in the previous layer. Each signal was attached with an importance weight $\boldsymbol{w} j$ $=\left[w_{1 j}, w_{2 j}, \ldots, w_{n j}\right]$. The combination function is usually linear; hence the potential was a weighted sum of the input values multiplied by the weights of the respective connections. This sum was compared with the value of the threshold. The potential of neuron $j\left(p_{j}\right)$ was defined by the following linear combination:

\section{Methodology}

$$
p_{j}=\sum_{i=0}^{n}\left(x_{i} w_{i j}\right)
$$

In this paper, it was assumed that all factors were related to the level of village development. So that all 31 factors were selected as the independent variables and the level of village development as the dependent variable as shown in Figure 3. Then ANN was applied to measure the weight/amount of impact, called "importance", for each independent variable affecting the level of rural village development.

\section{Figure 3: Conceptual Framework}

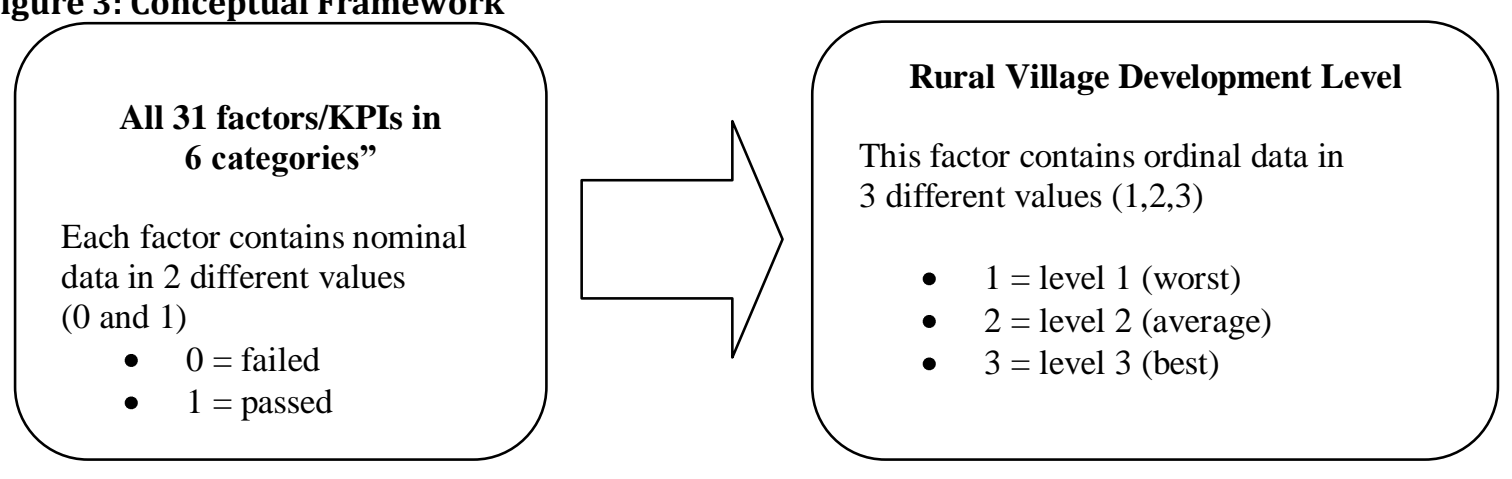

Back-propagation algorithm was selected as a main approach of ANN and it was set to run continually and re-process as looping until the expected accuracy was not less than $95 \%$, and then the analysis process was stopped. Once the weights of impact for each independent variable were retrieved. Then prioritized all of the weights of impact in descending order. The highest weight/importance was ranked $1{ }^{\text {st }}$, and the lowest weight/importance was $31^{\text {st }}$. 


\section{Results}

Table 2: A Summary of Factor Prioritization Affecting Thai Rural Development by Artificial Neural Networks (All Categories)

\begin{tabular}{|c|c|c|}
\hline $\begin{array}{c}\text { Factor Ranked } \\
\text { by Impact }\end{array}$ & Factor Name & $\begin{array}{l}\text { Score of } \\
\text { Impact }\end{array}$ \\
\hline 1 & Land Possession & 17.88 \\
\hline 2 & Electricity Access & 15.35 \\
\hline 3 & $\begin{array}{l}\text { Communication Technology Access (TV, Radio, } \\
\text { Internet) }\end{array}$ & 14.02 \\
\hline 4 & Educational Level & 12.06 \\
\hline 5 & Household Industry & 10.57 \\
\hline 6 & People Assembly & 10.55 \\
\hline 7 & Soil Quality & 7.56 \\
\hline 8 & Community Participation & 7.14 \\
\hline 9 & Water for Drinking & 6.17 \\
\hline 10 & Contagious Disease Prevention & 5.68 \\
\hline 11 & Getting A Job & 5.68 \\
\hline 12 & Work Safety & 5.53 \\
\hline 13 & Learning by A Community & 4.93 \\
\hline 14 & Being Educated & 4.64 \\
\hline 15 & Road & 4.57 \\
\hline 16 & Water for Consumption & 4.50 \\
\hline 17 & Sports & 4.09 \\
\hline 18 & Access of A Community's Financial Capital & 3.88 \\
\hline 19 & Water for Agriculture & 3.73 \\
\hline 20 & Water Quality & 1.76 \\
\hline 21 & Afforesting & 1.40 \\
\hline 22 & Environment Management & 1.30 \\
\hline 23 & Free from Addictive Drug & 1.21 \\
\hline 24 & Social Protection & 1.15 \\
\hline 25 & Products from Farms & 1.06 \\
\hline 26 & Products from Other Agriculture & 1.02 \\
\hline 27 & Land Utilization & 0.95 \\
\hline 27 & Products from Rice & 0.95 \\
\hline 29 & Benefits from Tourist Attraction & 0.88 \\
\hline 30 & Working in Establishment & 0.69 \\
\hline 31 & Further Studying beyond Regulation (Over Grade 9) & 0.58 \\
\hline
\end{tabular}

Estimated Accuracy: 95.60 \% from ANN, Input Layer: 31 neurons, Output Layer: 1 neuron

\section{Conclusion and Recommendations}

Referring to Table 2, the factor which has the most impact to Thai rural village development is "Land Possession" (17.88\%), the first runner-up is "Electricity" (15.35\%), the second runner-up is "Communication" (14.02\%), the third runner-up is "Educational Level" (12.06\%), and the forth runner-up is "Household Industry" (10.57\%). "Land Possession" has played the most important role in Thai rural development. This suggests that Thai government should keep on providing the title deeds or certificates of land ownership for agriculture to poor people in rural areas by Agricultural Land Reform Office (ALRO) established in 1975. Moreover ALRO has worked on this mission until present.

Furthermore, when consider "Natural Resources and Environment Category", "Soil Quality" has significantly more impact to Thai rural development than others. This corresponds to "Land Possession", the $1^{\text {st }}$ rank. It seems that the government should make policies for people to possess their land first. Because the findings show that it is more important than the quality of soil improvement and land utilization. The $2^{\text {nd }}$ and $3^{\text {rd }}$ impact factors, "Electricity Access" and "Communication Technology Access", which are related to information systems and technology, have slightly less impact. It seems likely that 
the information and communication technology (ICT) nowadays play a very important role in developing rural areas as well as urban areas. ICT helps provide useful information, news and knowledge to people which are the key capital of community development. So it seems very worth for the government to keep investing in ICT for covering all areas of Thailand.

The $5^{\text {th }}, 6^{\text {th }}, 8^{\text {th }}$ and $11^{\text {th }}$ impact factors, "Household Industry", "People Assembly", "Community Participation", and "Getting a Job", are classified into "Employment Category" mixed with "Community Strength Category". This finding could guide the government to promote grouping and participating of people and support them to make their household goods/products or jobs at the same time for earning their living. Owing to "Educational Level" is ranked $4^{\text {th }}$. So the government should pay more attention to educational policies to continually support and gain people's opportunities and accesses into all supported educational systems.

From the study, the findings show that 2 methods of prioritization referred in this study, either Statistical Frequency Distribution Analysis or ANN gives different results and different views. Statistical Frequency Distribution Analysis shows the number of villages which passed and failed. On the other hand, ANN shows how much impact of each factor. From now, the government or a policy maker should consider these results both in term of frequency and impact. Some problems might have been found in many villages (high frequency), but they have caused small impact to those villages. In contrast, some problems might have been rarely found (low frequency), but they have caused much impact to those villages.

Suggestions for Future Studies: A next researcher might change the database, the independent variable, or the dependent variable for extracting meaningful knowledge or try to use different ranking methods to compare the results with this method.

Acknowledgement: Particular thanks are given to the Community Development Department, Ministry of Interior, Thailand, which allowed the access to all national databases and resources with warm welcome and full support.

\section{References}

Bejou, D., Wray, B., and Ingram, T. N. (1996). Determinants of Relationship Quality: An Artificial Neural Network Analysis. Journal of Business Research, 36(2), 137-143.

Community Development Department (2003). Thai Rural Villages Report from Basic Village Information (NRD2C). Supatchanin Printing Group, Bangkok, Thailand.

Community Development Department. (2007). Thai Rural Villages Report from Basic Village Information (NRD2C). Supatchanin Printing Group, Bangkok, Thailand.

Community Development Department. (2007). The Life Quality of Thai Rural People Report from BMN Database. BTS Press, Bangkok, Thailand.

Grant, J. (2006). Planning the good community: New Urbanism in theory and Practice. Routledge, London, U.K. and New York, U.S.A.

Giudici, P. (2003). Representation of the activity of a neuron in a neural network [Painting]. Applied Data Mining: Statistical Methods for Business and Industry. By John Wiley \& Sons Ltd, West Sussex, England. 108.

Song, M., \& Zhao, Y. (2004). A Neural Network for Predicting Manufacturers' Perceived Cooperation with Distributors in the New Product Development Process. Journal of Business-to-Business Marketing, 11(3), 53-78.

Thieme, R. J., Song, M., \& Calantone, R. J. (2000). Artificial Neural Network Decision Support Systems for New Product Development Project Selection. Journal of Marketing Research, 37(4), 499-507.

West, P. M., Brockett, P. L., \& Golden, L. L. (1997). A Comparative Analysis of Neural Networks and Statistical Methods for Predicting Consumer Choice," Marketing Science, 16(4), 370-391.

Yesilyaprak, A. (2004). Bond Ratings with Artificial Neural Networks and Econometric Models. American Business Review, 22(1), 113-123. 